\title{
POTENSI CNG (COMPRESSED NATURAL GAS) SEBAGAI ALTERNATIF BAHAN BAKAR KAPAL PENANGKAP IKAN BERUKURAN PANJANG $11 \mathrm{M}$
}

\author{
CNG (COMPRESSED NATURAL GAS) POTENTION AS AN FUEL ALTERNATIVE FOR \\ 11 M LONG FISHING SHIP
}

\author{
Iman Anugerah Bintoro ${ }^{1)}$, Budhi Hascaryo Iskandar ${ }^{1)}$, Yopi Novita ${ }^{1)}$, Mohammad Imron ${ }^{1)}$ \\ Departemen Pemanfaatan Sumberdaya Perikanan, Fakultas Perikanan dan Ilmu Kelautan, Institut Pertanian Bogor, \\ Kampus IPB Darmaga, Bogor, 16680, Indonesia \\ E-mail:iman835@yahoo.com
}

Diterima tanggal: 5 Januari 2013, diterima setelah perbaikan: 14 Maret 2013., disetujui tanggal: 22 April 2013

\begin{abstract}
ABSTRAK
Nelayan dalam melaksanakan operasi penangkapan ikan mengalami tantangan dari berbagai faktor, terutama dalam hal pemenuhan kebutuhan ekonomi. Faktor eksternal yang menghambat adalah ikan impor yang menguasai pasar tradisional di sentra kelautan, cuaca buruk serta gelombang tinggi. Faktor internal yang menghambat adalah tingginya biaya operasional, terutama biaya bahan bakar yang merupakan variabel dominan dalam biaya operasional.Permasalahan harga bahan bakar bagi nelayan adalah masalah laten. Berdasarkan paparan diatas, perlu adanya upaya untuk mengurangi mengurangi ketergantungan terhadap ketersediaan bahan bakar minyak, dalam hal ini solar. Salah satu upaya yang dapat dilakukan adalah dengan menerapkan dual fuel dalam penggunaan bahan bakar kapal, yaitu mengkombinasikan penggunaan bahan bakar solar dengan Compressed Natural Gas (CNG). Tujuan dari penelitian ini adalah untuk melihat secara teknis apakah pemakaian bahan bakar tersebut menghasilkan keunggulan dan instalasinya tidak secara drastis mengurangi stabilitas kapal serta apakah secara ekonomis pemakaian bahan bakar tersebut dapat mengurangi biaya operasional. Metode yang digunakan dalam penelitian ini adalah eksperimental dalam menganalisa potensi operasional mesin serta simulasi numerik dalam menganalisa pengaruh instalasi sistem bahan bakar terhadap stabilitas kapal. Data akan dianalisa dengan menggunakan metode multi criteria analysis. Dari hasil penelitian diketahui bahwa pada potensi operasional mesin, bahan bakar dual fuel memiliki keunggulan baik secara teknis dan ekonomis, sedangkan pada potensi stabilitas kapal, secara teknis desain 2 memiliki stabilitas yang sama baik dengan desain 3. Pada potensi kombinasi, komposisi yang terbaik adalah penggunaan bahan bakar dual fuel dengan desain 3 .
\end{abstract}

Kata kunci : CNG, stabilitas, kapal, dual fuel, multi criteria analysis

\section{ABSTRACT}

Fuel costs spend $60 \%$ of operational cost. It is necessary to reduce dependency to international oil price. One of the efforts that can be done is use dual fuel (Compressed Natural Gas (CNG) + High Speed diesel (HSD)). This research purposes are to see if use of dual fuel technically superior than single fuel and the installation doesn't affect drastically to ship stability and economically could reduce fuel cost. Methods that used in this research are experimental in analyze potential of engine operation and numerical simulation with three CNG kit installation position (design) in analyze ship stability when using dual fuel. Data will be analyzed with multi criteria analysis method. From research result founded that from engine operational potential dual fuel superior and gave benefit. From stability potential, design 2 and design 3 have equal superiority. From potential combination, dual fuel with design 3 are the best option.

Key words : CNG, stability, ship, dual fuel, multi criteria analysis 


\section{PENDAHULUAN}

Permasalahan harga bahan bakar bagi nelayan adalah masalah laten. Hal ini disebabkan karena komponen terbesar dari biaya operasional penangkapan ikan bagi nelayan adalah biaya bahan bakar. Kebijakan subsidi dari Pemerintah pun tidak dirasakan merata di seluruh Indonesia

Berdasarkan paparan diatas, perlu adanya upaya untuk mengurangi mengurangi ketergantungan terhadap ketersediaan bahan bakar minyak, dalam hal ini solar. Salah satu upaya yang dapat dilakukan adalah dengan menerapkan dual fuel dalam penggunaan bahan bakar kapal. Dual fuel yang dimaksud adalah mengkombinasikan penggunaan bahan bakar solar dengan Compressed Natural Gas (CNG)

CNG kit memiliki dimensi yang cukup besar sehingga hanya cocok dipergunakan pada kapal dengan ukuran lebar diatas $2 \mathrm{~m}$. Penggunaan $\mathrm{CNG}$ kit mengakibatkan adanya penambahan muatan di atas kapal sebesar $80 \mathrm{~kg}$ dengan dimensi $109 \mathrm{~cm}$ x17 cm x $17 \mathrm{~cm}$ (P x L x T). Penambahan muatan di atas kapal akan mengakibatkan perubahan posisi titik berat yang pada akhirnya akan merubah posisi titik berat dan mempengaruhi kualitas stabilitas kapal.

Stabilitas adalah salah satu faktor utama kelaiklautan suatu kapal ikan saat beroperasi di laut. Hind (1967) menyatakan keselamatan pelayaran suatu kapal lebih banyak ditentukan oleh stabilitas. Stabilitas kapal adalah kemampuan kapal tersebut untuk kembali ke posisi semula setelah mengalami gaya-gaya tarik dari luar maupun dari dalam kapal yang menyebabkan kapal itu miring.

Berdasarkan pemaparan diatas, perlu dilakukan studi teknis pada potensi operasional mesin dan stabilitas kapal untuk melihat apakah pemakaian bahan bakar dual fuel tersebut menghasilkan keunggulan pada besarnya daya dan konsumsi solar pada mesin kapal serta apakah instalasinya tidak secara drastis mengurangi stabilitas kapal dan tetap memenuhi standar stabilitas yang ditentukan oleh International Maritime Organization.

Studi ekonomis pada potensi operasional perlu dilakukan untuk membandingkan biaya total konsumsi bahan bakar saat menggunakan dual fuel dan single fuel.

Pada penelitian ini, terdapat beberapa batasan yang digunakan, yaitu :

1) Mesin yang digunakan untuk pengujian adalah mesin Dong Feng ZS1100

2) Kajianteknis dibatasi pada operasional mesin dan stabilitas

3) kajian ekonomi terbatas pada harga total konsumsi bahan bakar.

Tujuan dari dilakukannya penelitian ini adalah :

1. membandingkan potensi operasional mesin secara teknis dan ekonomis saat menggunakan dual fuel dibandingkan dengan penggunaan single fuel.

2. Menentukan posisi penempatanCNG kit yang menghasilkan stabilitas terbaik pada kapal

3. Menentukan pilihan terbaik pada kombinasi potensi operasional mesin dan stabilitas.

Penelitian-penelitian mengenai CNG dan stabilitas kapal telah banyak dilakukan dalam 10 tahun terakhir. Penelitian - penelitian tersebut pada umumnya mengkaji pada umumnya mengkaji aspek teknis dari penggunaan $\mathrm{CNG}$ dan secara terpisah mengkaji stabilitas pada kapal yang berbeda. Berdasarkan hal tersebut, penelitian aspek teknis penggunaan dual fuel yang meliputi daya, konsumsi solar, dan stabilitas serta aspek ekonomis pada satu kapal yang sama perlu dilakukan.

Penelitian ini pada akhirnya melengkapi penelitian-penelitian terdahulu yang belum banyak mengkaji aspek teknis dan ekonomis terhadap potensi penggunaan dual fuel pada kapal penangkap ikan berukuran panjang 11 meter

\section{METODE PENELITIAN}

Penelitian dilakukan di laboratorium Balai Besar Pengembangan Penangkapan Ikan Kementrian Kelautan dan Perikanan yang bertempat di Semarang. Waktu penelitian adalah Bulan Oktober - Desember 2012.

Data pada penelitian ini diambil dengan menggunakan metode eksperimental pada potensi 
operasional mesin dan metode simulasi pada potensi stabilitas. Data yang dikumpulkan terdiri atas data utama dan data pendukung. Data utama terdiri dari output daya dan torsi, konsumsi solar, dimensi kapal ikan, perhitungan berat alat tangkap, perhitungan volume palka, berat dan dimensi instalasi CNG (termasuk tangki dalam keadaan penuh), dan kebutuhan es. Output daya, torsi, dan konsumsi bahan bakar didapatkan dari hasil penelitian Raharjo pada tahun 2009.

Data dimensi kapal ikan dan lines plan diambil dari penelitian Nugraha (2004) dan digambar ulang lalu dilengkapi oleh penulis hingga menghasilkan 3 desain general arrangement. Berat alat tangkap (gillnet) didapatkan dari simulasi perhitungan yang dikemukakan oleh Haudring (BBPPI), volume ruang palka dan kebutuhan es didapatkan berdasarkan rumus dari Shawyer dan Pizzali (2003), yaitu FHV $=\mathrm{L} \times \mathrm{B} \times \mathrm{D} \times 0,14 \pm 10 \%$ dan $\mathrm{M}_{\mathrm{i}}=\left(\mathrm{M}_{\mathrm{f}} \times \mathrm{T}_{\mathrm{fi}}\right) / 100$.

$\mathrm{M}_{\mathrm{i}}$ adalah massa dari es, $\mathbf{M}_{\mathrm{f}}$ adalah massa ikan yang akan didinginkan, $\mathrm{T}_{\mathrm{fi}}$ adalah temperatur tubuh ikan, L adalah panjang kapal, B adalah lebar kapal, dan D adalah tinggi dek. Merujuk pada Clarke dan Johnston (2002) dan Johnston et al. (1991), suhu tubuh ikan di perairan tropis adalah sebesar $30^{\circ} \mathrm{C}$.

Berat alat tangkap, volume ruang palka, kebutuhan es, dimensi CNG kit, jumlah nelayan, dan lines plan akan menjadi rujukan dalam merencanakan tiga desain general arrangement. Setiap desain general arrangement akan diberi simulasi untuk mengetahui kualitas stabilitas statis dari setiap desain. Hasil dari eksperimen pada potensi operasional mesin dan simulasi pada potensi stabilitas akan menjadi dasar dalam menilai aspek teknis dan ekonomis.

Terdapat beberapa perlakuan yang diberikan dalam penelitian ini. Pada potensi operasional mesin, perlakuan yang diberikan adalah dengan menggunakan sistem bahan bakar tunggal (single fuel) dan bahan bakar ganda (dual fuel). Adapun perlakuan yang diberikan pada potensi stabilitas adalah dengan membuat 3 desain penempatan sistem bahan bakar.

Parameter yang digunakan dalam menilai perlakuan yang diberikan adalah output daya, konsumsi solar, harga total konsumsi bahan bakar, area 0 to 30, area 0 to 40, area 30 to 40, initial GM, $\max$ GZ, angle at $\max G Z$. Tabel 1 menggambarkan perlakuan yang diberikan pada penelitian ini.

Tabel 1 Perlakuan pada tiap potensi (Research step for each potention)

\begin{tabular}{|c|c|c|c|}
\hline Potensi & Perlakuan & Parameter & keterangan \\
\hline $\begin{array}{l}\text { Operasion } \\
\text { al mesin }\end{array}$ & $\begin{array}{l}\text { Single fuel } \\
\text { Dual fuel }\end{array}$ & $\begin{array}{l}\text {-Output } \\
\text { daya } \\
\text {-Konsumsi } \\
\text { solar } \\
\text {-Harga total } \\
\text { konsumsi } \\
\text { bahan bakar }\end{array}$ & \\
\hline \multirow[t]{3}{*}{ Stabilitas } & Desain 1 & 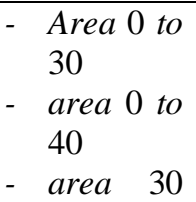 & $\begin{array}{l}\text { CNG kit } \\
\text { diletakkan } \\
\text { dibawah } \\
\text { geladak }\end{array}$ \\
\hline & Desain 2 & $\begin{array}{ll} & \text { to } 40 \\
- & \text { initial } \\
& G M \\
- & \max G Z\end{array}$ & $\begin{array}{l}\text { Mengguna } \\
\text { kan single } \\
\text { fuel }\end{array}$ \\
\hline & Desain 3 & $\begin{array}{l}-\quad \text { angle at } \\
\max G Z\end{array}$ & $\begin{array}{l}\text { CNG kit } \\
\text { diletakkan } \\
\text { diatas } \\
\text { geladak }\end{array}$ \\
\hline
\end{tabular}

Pada pengukuran output daya dan konsumsi solar, dilakukan pada putaran $1100 \mathrm{rpm}, 1400 \mathrm{rpm}, 1500$ rpm, dan $1800 \mathrm{rpm}$. Adapun nilai yang dibandingkan adalah pada putaran $1500 \mathrm{rpm}$, karena putaran tersebut merupakan service continous rating yang digunakan oleh nelayan saat operasi penangkapan ikan berlangsung.

Asumsi yang digunakan adalah nelayan berjumlah empat orang, palka dalam keadaan penuh, dan berat solar disamakan dengan berat CNG. Data pendukung yang akan diambil adalah Process Flow Diagram instalasi bahan bakar CNG, dan specification sheet dari mesin diesel

Pada penelitian ini, data yang telah dikumpulkan melalui eksperimen dan simulasi akan dianalisa dengan menggunakan metode multi criteria analysis. Metode multi criteria analysis adalah metode analisa yang menggunakan sistem skoring dan standarisasi (bobot) untuk menemukan kombinasi perlakuan yang terbaik dari semua perlakuan yang ada. 
Pada penelitian ini, perlakuan yang digunakan adalahsingle fuel, yaitu mesin kapal hanya menggunakan satu jenis bahan bakar, yaitu solar dan dual fuel, yaitu mesin kapal menggunakan dua jenis bahan bakar, yaitusolar-CNG. Tabel 2menggambarkan interval skor pada berbagai variabel.

Tabel 2 Interval skor untuk berbagai variabel (Score interval for each variables)

\begin{tabular}{lcl}
\hline \multicolumn{1}{c}{ Variabel } & $\begin{array}{c}\text { Interval } \\
\text { skor } \\
1-7\end{array}$ & Satuan \\
$\begin{array}{l}\text { Daya } \\
\text { Konsumsi bahan bakar }\end{array}$ & $\begin{array}{l}\text { Horse power } \\
\mathrm{cm}^{3} / \mathrm{h}\end{array}$ \\
$\begin{array}{l}\text { Harga total konsumsi } \\
\text { bahan bakar }\end{array}$ & $1-7$ & Rupiah \\
Luas area $0^{\circ}-30^{\circ}$ & $1-7$ & m.deg \\
Luas area $0^{\circ}-40^{\circ}$ & $1-7$ & m.deg \\
Luas area $30^{\circ}-40^{\circ}$ & $1-7$ & m.deg \\
Max GZ & $1-7$ & Meter \\
Angle at max GZ & $1-7$ & Derajat \\
Initial GM & $1-6$ & Meter \\
\hline
\end{tabular}

Langkah selanjutnya adalah melakukan standarisasi (pembobotan) pada setiap variabel dalam kriteria/aspek teknis dan ekonomis. Skoring dan standarisasi akan menghasilkan nilai kualitas yang akan menjadi dasar penentuan penggunaan jenis bahan bakar apa yang memberikan keunggulan teknis dan keuntungan ekonomis terbaik, desain sistem instalasi bahan bakar seperti apa yang akan memberikan stabilitas terbaik, serta kombinasi pemakaian bahan bakar dan desain sistem instalasi bahan bakar apakah yang terbaik.

\section{HASIL DAN PEMBAHASAN}

\subsection{Potensi operasional mesin \\ 3.1.1. Aspek teknis}

Terdapat perbedaan output daya yang didapatkan pada mesin diesel Dong Feng ZS1100 saat menggunakan single fuel dan dual fuel. Hasil pengambilan data menunjukkan bahwa terdapat perbedaan output daya mesin saat menggunakan bahan bakar single fuel dan dual fuel. Pada putaran $1500 \mathrm{rpm}$, daya yang didapatkan sebesar 7,51 Hp saat menggunakan single fuel dan sebesar 5,5 Hp saat menggunakan dual fuel. Hal ini sesuai dengan penelitian yang dilakukan oleh Setiyobudi et al. (2009) bahwa didapatkan perbedaan output daya saat mesin kapal nelayan di Pasuruan menggunakan bahan bakar yang berbeda, dimanaoutput daya yang didapatkan lebih besar saat mesin menggunakan single fuel.

Terdapat suatu hal yang cukup unik, CNG dikenal sebagai bahan bakar dengan octane number yang tinggi sehingga seharusnya cocok pada mesin dengan kompresi tinggi dan dapat meningkatkan performa. Berdasarkan hasil percobaan, terdapat kenaikan putaran mesin di putaran stasioner saat menggunakan dual fuel.

Berdasarkan rumus perhitungan daya $(7 \mathrm{x}$ area of piston $x$ equivalent piston speed/33000) (Wikipedia.org/horsepower), seharusnya daya akan bertambah bila putaran mesin bertambah. Fakta yang ada menunjukkan bahwa hasil pengujian memperlihatkan terjadinya penurunan daya saat menggunakan dual fuel.

Merujuk pada Ganesan (1999), dijelaskan bahwa CNG memiliki octane number yang besar sehingga dapat digunakan pada mesin dengan kompresi tinggi. Kekurangan yang ada pada $\mathrm{CNG}$ adalah massa jenis yang rendah sehingga menghasilkan performa mesin yang kurang baik. Merujuk pada laman www.eere.energy.gov/afdc/altfuel/ natural_gas.html, dijelaskan bahwa pemakaian CNG akan menyebabkan mesin mengalami gejala ngelitik (knocking) saat mendapat beban yang tinggi.

Hal ini menjelaskan mengapa saat menggunakan dual fuel,pada putaran diatas $1600 \mathrm{Rpm}$ daya mesin akan berkurang, dan pada saat menggunakan single fuel daya akan terus meningkat dan mencapai puncaknya pada putaran $2096 \mathrm{rpm}$.

Merujuk pada Semin et al. (2012), dinyatakan bahwa perubahan rasio kompresi akan berpengaruh pada performa mesin diesel. Mesin diesel umumnya memiliki rasio kompresi 20:1 hingga 26:1, sedangkan CNG dengan RON 130 cocok dengan mesin dengan rasio kompresi 16:1. Simulasi yang dilakukan dengan menggunakan perangkat lunak GT Power menghasilkan bahwa diperlukan penurunan kompresi hingga 19:1 untuk menghasilkan daya maksimal karena jika rasio 
kompresi diatas 19:1 akan terjadi knocking (ngelitik) sehingga daya mesin akan berkurang.

Perbedaan yang signifikan terjadi pada konsumsi solar di mesin diesel Dong Feng ZS1100 saat menggunakan single fuel dan dual fuel selama satu jam, yaitu $1030 \mathrm{~cm}^{3} / \mathrm{h}$ saat menggunakan dual fuel dan $2038,5 \mathrm{~cm}^{3} / \mathrm{h}$ saat menggunakan single fuel.

Merujuk pada Prasetio et al. (2013), dinyatakan bahwa dengan adanya campuran CNG pada sistem bahan bakar, konsumsi solar akan terkurangi secara signifikan hingga diatas 50\%. Hasil ini tidak berbeda jauh dengan data yang didapatkan peneliti, yaitu konsumsi solar terkurangi sebesar 50,52\%

\subsubsection{Aspek ekonomis}

Pada putaran $1500 \mathrm{rpm}$, biaya total saat menggunakan dual fuel akan lebih rendah dibandingkan saat menggunakan single fuel. Pada putaran $1100 \mathrm{rpm}$, biaya total yang dikeluarkan untuk konsumsi bahan bakar lebih tinggi saat menggunakan dual fuel, namun ketika putaran mesin mencapai $1500 \mathrm{rpm}$ maka biaya total saat menggunakan dual fuel akan lebih rendah. Terdapat penghematan sebesar Rp. 1370 untuk setiap jam pemakaian mesin pada putaran 1500 rpm.

Merujuk pada Prasetio et al. (2013), dinyatakan bahwa pemakaian dual fuel yang setara dengan 10 liter solar akan memberikan penghematan hingga Rp. 16.500. Pemakaian bahan bakar dual fuel terbukti dapat mengurangi pengeluaran biaya bahan bakar sehingga akan mengurangi biaya operasional.

Berdasarkan hasil kajian peneliti, perbedaan harga CNG dan solar hanya terpaut Rp. 1,700 per liter, bahkan terdapat kabar bahwa harga CNG akan dinaikkan sehingga selisih harganya hanya sebesar Rp. 1,500 per liter. Perbedaan harga yang tidak terlalu jauh menyebabkan penghematan yang didapat tidak terlalu besar.

Penghematan yang signifikan akan didapatkan bila selisih harga solar dan CNG sebesar Rp. 3.200. Tabel 3 menggambarkan penghematan yang akan didapatkan pada selisih harga Rp. 700 dan Rp. 3,200, sedangkan Tabel 4 dan Tabel 5 menggambarkan hasil perhitungan multi criteria analysis pada penggunaan single fuel dan dual fuel.

Tabel 3Penghematan biaya bahan bakar (Fuel cost reduce)

\begin{tabular}{lccc}
\hline $\begin{array}{c}\text { Selisih } \\
\text { harga } \\
(\mathbf{R p})\end{array}$ & $\begin{array}{c}\text { Harga } \\
\text { single fuel } \\
(\mathbf{R p})\end{array}$ & $\begin{array}{c}\text { Harga } \\
\text { dual fuel } \\
(\mathbf{R p})\end{array}$ & $\begin{array}{c}\text { Penghematan } \\
(\mathbf{R p})\end{array}$ \\
\hline $\mathbf{7 0 0}$ & 9172,5 & 7802 & 1370,5 \\
\hline $\mathbf{3 2 0 0}$ & 14268,33 & 9077 & 5191,33 \\
\hline
\end{tabular}

Tabel 4Multi criteria analysis potensi operasional mesin pada penggunaansingle fuel

( engine operational potention's multi criteria analysis at single fuel usage)

\begin{tabular}{lcccc}
\hline $\begin{array}{l}\text { Kriteria teknis dan } \\
\text { ekonomis }\end{array}$ & Solar & Skor & Bobot & Jumlah \\
\hline $\begin{array}{l}\text { Daya saat } \\
\text { menggunakan } \\
\text { solar (HP) 7,512 }\end{array}$ & $\mathbf{0 , 0 6}$ & $\mathbf{0 , 1 2}$ & & \\
$\begin{array}{l}\text { Konsumsi } \\
\text { Solar(cm }\end{array}$ /h) & $\mathbf{2 0 3 8 , 3 2}$ & $\mathbf{0 , 2 2}$ & $\mathbf{0 , 4 3}$ & \\
$\begin{array}{l}\text { Harga } \\
\text { konsumsi } \\
\text { solar (Rp) }\end{array}$ & $\mathbf{9 1 7 2 , 5 2}$ & $\mathbf{0 , 7 2}$ & $\mathbf{1 , 4 5}$ & \\
\hline & & & & \\
& & & Jumlah & 2 \\
\hline
\end{tabular}

Tabel 5Multi criteria analysispotensi operasional mesin pada penggunaan dual fuel

(engine operational potention's multi criteria analysis at dual fuel usage)

\begin{tabular}{|c|c|c|c|}
\hline $\begin{array}{l}\text { Kriteria teknis dan } \\
\text { ekonomis }\end{array}$ & $\begin{array}{l}\text { Dual skor } \\
\text { fuel }\end{array}$ & Bobot & Jumlah \\
\hline $\begin{array}{l}\text { Daya saat } \\
\text { menggunakan } \\
\text { solar+CNG }(\mathrm{HP}) \\
\text { Konsumsi } \\
\text { solar }\left(\mathrm{cm}^{3} / \mathrm{h}\right) \\
\text { Harga } \\
\text { konsumsi } \\
\text { solar+CNG (Rp) }\end{array}$ & $\begin{array}{l}5,510,06 \\
103050,22\end{array}$ & $\begin{array}{r}0,06 \\
1,08\end{array}$ & \\
\hline
\end{tabular}

Tabel 3 - 5 memperlihatkan bahwa pemakaian dual fuel yang setara dengan 10 liter solar akan memberikan penghematan hingga Rp. 19,800 bila selisih harga antara solar dan CNG sebesar Rp 3,200, sedangkanselisih harga antara solar dan CNG sebesar Rp 700 akan menghasilkan penghematan sebesar Rp 7,300. 
Tabel 4 dan 5 memperlihatkan bahwa saat menggunakan dual fuel konsumsi solar dan harga total konsumsi bahan bakar lebih unggul dibandingkan saat menggunakan single fuel. Keunggulan penggunaan single fuel ada pada variabel daya yang dihasilkan, yaitu 23\%lebih besar jika dibandingkan dengan penggunaan dual fuel. Keunggulan dual fuel pada konsumsi solar dan harga total konsumsi bahan bakar lebih besar masing-masing $50,52 \%$ dan $15 \%$ jika dibandingkan dengan penggunaan single fuel.

Berdasarkan analisa diatas dapat disimpulkan bahwa secara teknis dan ekonomis penggunaan dual fuel pada mesin Dongfeng ZS1100 lebih unggul dengan perbandingan skoring 3,31 dan 2 .

\subsection{Potensi Stabilitas kapal}

Dua prinsip pokok dalam perhitungan stabilitas adalah prinsip kenyamanan dan prinsip keselamatan. Kenyamanan kapal sangat tergantung pada nilai GM, jika terlalu rendah maka sudut olengan kapal akan besar sehingga periode olengan pun akan relatif besar dan mengurangi kenyamanan. Nilai GM akan kecil bahkan negatif bila peletakan muatan terkonsentrasi diatas permukaan dek. Bila nilai GM terlalu besar maka sudut olengan kapal akan terlalu kecil sehingga periode olengan kapal kecil yang mengakibatkan gerakan rolling kapal menyentak-nyentak (Hardjanto, 2010).

Kapal gillnet yang diteliti memiliki nilai GM sebesar 0,414. Nilai ini cukup ideal karena berada diatas batas minimal (0,35 menurut IMO) namun tidak terlalu besar nilainya. Keselamatan kapal sangat dipengaruhi oleh nilai GZ. Besar kecilnya nilai GZ menentukan keselamatan kapal, karena momen penegak atau momen static stability memiliki rumus $\mathrm{W} \times \mathrm{GZ}$. $\mathrm{W}$ adalah volume displacement dan GZ adalah lengan penegak. GZ merupakan ukuran kemampuan kapal untuk kembali tegak setelah kapal mengalami kemiringan akibat pengaruh dari gaya - gaya eksternal. IMO (International Maritime Organization) memberikan kriteria standar stabilitas kapal yang digambarkan dalam Tabel 6 .
Tabel 6 Standar Stabilitas kapal oleh IMO (Stability standart by IMO)

\begin{tabular}{lc}
\hline Kriteria & Standar minimal \\
\hline Area $0^{\circ}-30^{\circ}$ & $3,151 \mathrm{~m} \cdot \mathrm{deg}$ \\
\hline Area $0^{\circ}-40^{\circ}$ & $5,157 \mathrm{~m} \cdot \mathrm{deg}$ \\
\hline Area $30^{\circ}-40^{\circ}$ & $1,719 \mathrm{~m} \cdot \mathrm{deg}$ \\
\hline Maximum GZ & $0,2 \mathrm{~m}$ \\
\hline Angle at maximum GZ & $25^{\circ}$ \\
\hline GMT for fishing vessel & $0,35 \mathrm{~m}$ \\
\hline
\end{tabular}

Sumber :Muckle, 1978.

Ukuran utama kapal yang akan diuji stabilitasnya memiliki panjang $(\mathrm{L})=11,8842 \mathrm{~m}$; lebar $(\mathrm{B})=2,5$ $\mathrm{m}$; tinggi geladak $(\mathrm{H})=1,0 \mathrm{~m}$; tinggi sarat $(\mathrm{T})=$ $0,75 \mathrm{~m}$; koefisien blok $(\mathrm{Cb})=0,51$. Alat tangkap yang digunakan oleh kapal ini adalah gillnet. Berdasarkan perangkat lunak yang dibuat oleh Haudring, didapatkan berat gillnet sebesar $155 \mathrm{~kg}$.

Nelayan yang berada di kapal selama proses penangkapan ikan adalah sebanyak empat orang dengan berat masing - masing diasumsikan seberat $75 \mathrm{Kg}$. Berdasarkan perhitungan dari Sawyer dan Pizzali(2003) didapatkan berat es sebesar $600 \mathrm{~kg}$, sedangkan kapasitas palka direncanakan sebesar $1880 \mathrm{Kg}$ dan berat CNG kit sebesar $80 \mathrm{Kg}$.

Pengujian yang dilakukan pada kapal pembanding gillnet berukuran panjang (L) 10,50 m, Lebar (B) $2,19 \mathrm{~m}$, dan tinggi geladak $(\mathrm{H}) 0,85 \mathrm{~cm}$ dengan mesin outboard instalasi menyamping dan panjang poros diatas 2,5 m kapal dapat dijalankan dengan kecepatan 7 knot (Setiyobudi et al. 2009), sedangkan bila dilakukan simulasi dengan piranti lunakdesain kapal, maka kapal dapat dijalankan hingga kecepatan 7,25 knot saat beban maksimal (maximum load).

Terdapat tiga desain instalasi sistem bahan bakar (Tabel 7). Desain satu (loadcase 1) adalah menggunakan bahan bakar dual fuel dengan penempatan CNG dibawah geladak dan dalam tempat tertutup (confined area). Desain dua (loadcase 2) adalah menggunakan bahan bakar single fuel dengan penambahan bahan bakar cadangan sebanyak $50 \mathrm{~kg}$, sedangkan desain tiga (loadcase 3) menggunakan bahan bakar dual fuel dengan penempatan CNG kit diatas geladak. 
Tabel 7 Multi criteria analysis potensi stabilitas kapal

\begin{tabular}{|c|c|c|c|c|c|c|c|c|c|c|c|}
\hline Kriteria stabilitas & $\begin{array}{l}\text { Desain } \\
1\end{array}$ & $\begin{array}{c}\text { Desain } \\
2\end{array}$ & $\begin{array}{c}\text { Desain } \\
3\end{array}$ & Std & $\begin{array}{c}\text { Skor } \\
1\end{array}$ & $\begin{array}{c}\text { Skor } \\
2\end{array}$ & $\begin{array}{c}\text { Skor } \\
3\end{array}$ & bobot & Jml 1 & Jml 2 & Jml 3 \\
\hline Area 0 to 30 & 3,183 & 3,297 & 3,292 & 3,151 & 2 & 2 & 2 & 0,04 & 0,08 & 0,08 & 0,08 \\
\hline Area 0 to 40 & 5,643 & 5,793 & 5,782 & 5,157 & 2 & 3 & 3 & 0,052 & 0,1 & 0,15 & 0,15 \\
\hline Area 30 to 40 & 2,46 & 2,495 & 2,49 & 1,719 & 4 & 4 & 4 & 0,04 & 0,16 & 0,16 & 0,16 \\
\hline Max GZ at 30 & 0,301 & 0,294 & 0,293 & 0,2 & 4 & 4 & 4 & 0,456 & 1,82 & 1,82 & 1,82 \\
\hline Angle at max GZ & 56,5 & 54,5 & 54,5 & 25 & 5 & 5 & 5 & 0,241 & 1,2 & 1,2 & 1,2 \\
\hline $\begin{array}{l}\text { Initial GM for } \\
\text { fishing vessel }\end{array}$ & 0,396 & 0,414 & 0,414 & 0,35 & 3 & 3 & 3 & 0,172 & 0,51 & 0,51 & 0,51 \\
\hline & & & & & & & & Jumlah & 3,89 & 3,94 & 3,94 \\
\hline
\end{tabular}

Desain 1 sangat tidak dianjurkan pada kapal kecil, karena merujuk pada Guidelines for the Use of Gas as Fuel for Ships yang dikeluarkan oleh GL(2010), dinyatakan bahwa tangki gas dengan tekanan diatas 10 bar tidak boleh diletakkan di ruang tertutup tanpa ventilasi yang memadai.

Perhitungan software memperlihatkan pula bahwa semua desain memenuhi kriteria teknis. Dengan panjang kapal (L) 11,8 m, lebar kapal (B) 2,5 m, dan tinggi geladak $(\mathrm{H}) 1 \mathrm{~m}$ didapatkan nilai maksimum GZ sebesar 0,301 m;0,294 m;0,293 m, sudut saat GZ maksimal sebesar $56,5^{\circ} ; 54,5^{\circ} ; 54,5^{\circ}$, dan nilai GM sebesar 0,396 m;0,414 m;0,414 m. Tabel 7pada lampiran menggambarkan hasil multi criteria analysis pada kriteria teknis dalam potensi stabilitas.

Desaindua (single fuel) memiliki keunggulan pada luas area $0^{\circ}-30^{\circ}$, luas area $0^{\circ}-40^{\circ}$, luas area $30^{\circ}-40^{\circ}$, dan initial GM. Desainsatu (dual fuel, CNG kit diletakkan di bawah) memiliki keunggulan pada maximum GZ dan angle at maximum GZ. Desaintigalebih unggul pada luas area $30^{\circ}-40^{\circ}$, dan initial GM.

Analisa diatas memperlihatkan bahwa secara keseluruhan desain dua dan desain tiga lebih unggul dalam potensi stabilitas dengan perbandingan skoring 3,94 dan 3,89. Kombinasi dua potensi (operasional mesin dan stabilitas kapal) menunjukkan bahwa keunggulan tertinggi dimiliki oleh kapal saat menggunakan dual fuel dengan $\mathrm{CNG}$ kit diletakkan di atas dek yang mendapatkan skor sebesar 7,25. Kapal saat menggunakan dual fuel dengan CNG kit diletakkan di bawah memiliki skor sebesar 7,2 dan kapal menggunakansingle fuel memiliki skor sebesar 5,94 .

\section{KESIMPULAN DAN SARAN}

\section{Kesimpulan}

Pada potensi operasional mesin, penggunaan dual fuel pada mesin Dongfeng ZS1100 lebih unggul jika dibandingkan dengan penggunaan single fuel.

Pada potensi stabilitas, penggunaan single fueldan penempatan CNG kit diatas dek lebih unggul.

Pada potensi kombinasi, yang paling unggul adalah kapal menggunakan dual fuel dengan CNG kit diletakkan di atas dek

\section{Saran}

1. Perlu ditambahkan kriteria emisi dan reliabilitas pada kriteria tekno ekonomi

2. Pada kriteria stabilitas dapat dikembangkan hingga meneliti seakeeping pada tiap skema instalasi 
3. Penelitian pengembangan yang dapat dilakukan adalah analisis ekonomi operasi penangkapan ikan dengan skema instalasi dual fuel dan CNG kit diletakkan di atas dek.

\section{UCAPAN TERIMA KASIH}

Pada kesempatan ini saya ingin berterima kasih kepada Balai Besar Pengembangan Penangkapan Ikan, Kementrian Kelautan dan Perikanan sehingga penelitian ini dapat terselesaikan

\section{DAFTAR PUSTAKA}

Clarke A, Johnston NM. 2002. Scaling of metabolic rate with body mass and temperature in teleost fish. Journal of animal ecology. 68:893-905.

[GL] Germanischer Llyodd (DE). 2010. Rules for Classification and Construction Chapter VI Part 3 Guidelines for The Use Of Gas as Fuel for Ships. Germany (DE):[penerbit tidak diketahui]

Hardjanto A, 2010. Pengaruh kelebihan dan pergeseran muatan di atas kapal terhadap stabilitas kapal. Jurnal aplikasi pelayaran dan kepelabuhanan. 1(1):1-17

Hind JA, 1967. Stability and Trim of Fishing Vessel. London (GB): Fishing new books ltd.

Johnston IA, Clarke A, Ward P. 1991. Temperature and metabolic rate in sedentary fish from the antarctic, north sea, and indo west pacific ocean. Marine biology. 109:191-195

Muckle W. 1978. Naval Architecture of Marine Engineers. [tempat tidak diketahui]. New butterword and co.

Nugraha Y. 2004. Bentuk Geometris Kapal Payang Dan Gillnet Yang Beroperasi Di Teluk Pelabuhan Ratu, Sukabumi, Jawa Barat (repository IPB). Bogor (ID): Institut Pertanian Bogor

Raharjo O, Asikin Z. 2009. Penggunaan Bahan Bakar Gas Pada Motor Penggerak Kapal Perikanan. Semarang (ID): [penerbit tidak diketahui]
Shawyer M, Pizzali AFM. 2003. The Use of Ice On Small Fishing Vessels. Rome (IT): FAO fisheries technical paper.

Semin S, Bakar RA, Ismail AR. 2008. Application review of compressed natural gas as a sustainable alternative fuel in the internal combustion engines. $I^{\text {st }}$ international conference of the institution of engineering and technology; 2008 May 26-28; Brunei Darussalam. Brunei Darussalam: Brunei Darussalam Network.

Semin S, Dayang, Amiadji, Zuhdi A, Ariana IM. 2012. Pengaruh perubahan compression ratio motor diesel menggunakan bahan bakar gas dan efeknya terhadap power dan daya. Seminar nasional teori dan aplikasi teknologi kelautan; 2012 Des 5; Indonesia (ID): hlm X1-X5

Setiyobudi N, Asikin Z, Rahardjo O, Budihardjo. 2011. Bahan Bakar Gas (CNG) Alternatif Pengganti BBM Kapal Perikanan. [penerbit tidak diketahui].

[penulis tidak diketahui]. Natural gas [Internet]. [Diunduh pada 2013 Apr 20]. Tersedia pada www.eere.energy.gov/afdc/altfuel/natural_g as.html

[penulis tidak diketahui]. Horse power [Internet]. [Diunduh 2013 Apr 20]. Tersedia pada www.Wikipedia.org/horsepower. 